\title{
Dietary Milk Consumption and the Pesticide Residues Exposure from Pasteurized and UHT samples
}

\author{
Ciscato $\mathrm{CHP}^{1 *}$, Barbosa $\mathrm{CM}^{1}$, Gebara $\mathrm{AB}^{1}$ and $0 z a w a \mathrm{KS}^{2}$ \\ ${ }^{1}$ Instituto Biológico - São Paulo, Brazil \\ ${ }^{2}$ Agilent Technologies Brasil Ltda, Brazil
}

*Corresponding author: Ciscato CHP, Instituto Biológico - São Paulo, Av: Conselheiro

\section{Research article \\ Volume 3 Issue 2}

Received Date: March 03, 2018

Published Date: April 20, 2018

Rodrigues Alves, 1252, CEP: 04014-002, SP, Brazil, Tel: +5511 50871732; Email: ciscato@biologico.sp.gov.br

\section{Abstract}

The multi residue analysis with QuEChERS sample preparation method was employed to evaluate cow milk samples containing up to $3 \%$ of fat. After the cleanup step with C18, the pesticides were analyzed by Agilent 7890A GC and 7000B Triple Quadrupole GC/MS/MS System. Two analytical methods were established, for screening andfor quantification. The quantitativemethod was validated in terms of recovery and reproducibility.A total of 28 samples of milk (pasteurized and UHT) purchased at Sao Paulo markets were evaluatedby these two methods. The pesticides chlorpyrifos and cypermethrin were the most frequent, probably due to their use intick controlin bovines. All the positive sample results were below the LOQ and the acute dietary intake parameter was not extrapolated. The method was feasible for the propose of monitoring the food quality in which content of fat at $3 \%$ can compromise the chromatography system if the cleanup is not enough.

Keywords: Pesticide Residues; Milk; Multi residue Method; QuEChERS; LOQ

Abbreviations: MCL: Maximum Concentration Levels; UHT: Ultra-Heated Treatment; PNCRC: National Program of Animal Control of Residues and Contaminants; ADI: Acceptable Dietary Intake.

\section{Introduction}

An essential source of nutrients for all ages is cow milk. Brazil is the fourth great producers in the world with 34 billion of liters in 2013 according to Livestock and Agricultural Ministry and around 100g per day of milk and dairy products are consumed by an adult [1]. In fact, children and elderly people consume almost a liter per day and their exposure to contaminants in milk is a health risk concern. Governmental Agencies, in general, check the compliance of the milk and its adulteration, frauds and particularly microbiological control. However, many compounds like pesticides can be secreted to the milk bycontaminated feed consumption and parasite control application. Pesticides represent a risk to human, environmental and animal health; the evaluation of such compounds should involve monitoring programs on food control, especially for chemical persistent contaminants and misuse of such substances during food production.

There is a constant concern regarding the environmental contamination like drinking water and soil that can lead to contaminate humans and animals [2,3]. Nevertheless, we have no consistent values for maximum concentration levels (MCL) from many jurisdictions that 
should guarantee that there is no risk due to the exposition to those pesticides from contaminated environment and food.

This study evaluated the presence of pesticide in milk mainly originated from application of veterinary drugs of those persistent compounds for pest control and in minor proportion due to environmental contamination through water and soil. Brazilian regulation controls the presence of some substances that are used directly on the animal or to the places that they stay mostly. To verify the presence and its concentration of those substances in consumed milk, this study focused the analysis of those compounds commonly allowed to use according to MAPA and some others to CODEX specification for pesticide in milk.

Animal products like milk, can accumulate pesticides residues through contaminated feed, grass/hay and veterinary drugs used to control endo and ectoparasites. Such substances have fat solublechemical characteristics, contributing to its residual presence. Brazilian Maximum Residues Level enforcement, normative no13 compiles mycotoxins, antibiotics, carbamates, organophosphorus and pyrethroids insecticides and acaricides as regulated substances [4]. The organochlorinated compounds had its use prohibited by legislation no. 329 in the 80's and the national programs do not investigate anymore. However, it was used until ninety's in some specific situation like public health campaign and vector control diseases.

Considering the importance of milk and dairy products in human health, thereare few articles published for monitoring pesticide residues in milk in Brazil Ciscato, et al. Freguglia, et al. Pagnani, et al. [5-7]. The present work has the objective of evaluate the milk samples collected in supermarkets. Positive samples were compared to legislation and their toxicological contributions were evaluated.

\section{Materials and Methods}

\section{Milk Samples}

Today, the most common milk found in supermarkets is Ultra-Heated Treatment (UHT) type nevertheless pasteurization process is frequently used. Both processes are used to control bacteria's growth. Such process can extend the shelf life as well as affect the pesticide residues concentration. Milk homogenization is another type of milk process, which consists in maintain the integrity of lipids and aqueous phases. Chemical constituents of milk are lipids, water, proteins, vitamins, mineral salts, which their quantity depend on the animal species and the period of the year. Brazilian cattle produce milk with almost $6 \%$ of lipids. According to legislation, the dairy producers can reduce such percentage up to $3 \%$ so it can be considered as whole milk. Therefore, all samples purchased were this type of milk with $3 \%$ of fat content (except organic milk) making possible to have enough sample cleanup using QuEChERS method with C18 in the cleanup step.

It was collected 28 samples of milk, half of them in the first semester to verify the presence of pesticides according to climate characteristics in the period. The categories organic ( $6 \%$ of lipids), pasteurized and UHT (both 3\% of lipids) were evaluated for pesticide residues.

\section{Pesticides}

The pesticides used to verify the method are some listed in National Program of Animal Control of Residues and Contaminants (PNCRC and from Codex Alimentarius $[1,8]$. They are from classes like organochlorines, PCBs, representative organophosphorus, carbamates and pyrethroids. The acaricide amitraz largely used in Brazil was evaluated, as well the DMF $(2,4$ dimethylphenyl formamidine) metabolite. The legislation allows the usage of such substances, however, the withdrawal period described on drug leaflet, which can range between some hours to some days, according to the substances after its pulverization, bath or application should be followed [9]. Other pesticides commonly used as tick control, such as ivermectin group, were not evaluated in this study because of the compound's characteristics which are unsuitable for gas chromatography technique.

\section{Acceptable Dietary Intake (ADI) and Ccalpha/CCbeta Criteria}

The criteria were evaluated for positive samples and considered the concentration found in the sample, the consumption data from National Institute the limits from recovery samples and the calibration curves [10].

Pesticide residue contribution was calculated employing the principles from JMPR (Joint Meeting on Pesticide Residues) in which update and expand the report of the Joint FAO/WHO consultation on Food Consumption and Exposure Assessment [11]. According to these principles, the acceptable dietary intake is calculated in $\mathrm{mg} /$ person/day or $\mathrm{mg} /$ body weight/day considering the body weight (bw) of an adult as $60 \mathrm{~kg}$ and the concentration of chemical in food by food consumption.

The values from dietary exposure were compared with the ADI (\%ADI <100) and the percentage of pesticide residue contribution was calculated. The Cc alpha/CC beta parameters were calculated as established by MAPA [1]. 


\section{Quality Control}

To achieve the international requirements, the LRP is accredited in ISO 17025 . The validation studies accomplished the criteria for analytical performance Thompson, et al. [12]. The LRP participate annually in proficiency testing schemes with satisfactory performances. The recoveries are generally in 70 to $120 \%$.

\section{Reagents and Analytical Standards}

Acetonitrile, isooctane, and acetone were pesticideresidue grade. Pure standards from AccuStandard, around $99 \%$ pure, were used to prepare stock solutions at 1,000 $\mathrm{ng} / \mu \mathrm{L}$ and working solutions that varied in concentration.

\section{Analytical Steps}

The extraction was performed using $10 \mathrm{~g}$ of bovine milk and $10 \mathrm{~mL}$ of acetonitrile, after shaking, QuEChERS salts ( $4 \mathrm{~g} \mathrm{MgSO}_{4}, 1 \mathrm{~g} \mathrm{NaCl}, 1 \mathrm{~g}$ Na citrate, and $0.5 \mathrm{~g}$ disodium citrate sesquihydrate) were added and agitated for 2 minutes. The presence of $3 \%$ of fat in bovine milk commercialized in Brazil could affect the chromatographic performance requiring more maintenance. Therefore, fat acids were removed by using a subsequent dispersive cleanup designed to include fat removal, the SPE Dispersive containing $150 \mathrm{mg}$ PSA, 150 $\mathrm{mg} \mathrm{C} 18 \mathrm{EC}$, and $900 \mathrm{mg} \mathrm{MgSO}_{4}$.

\section{Fortified Samples}

The same procedure was used to evaluate the spiked samples. The recovery study was carried out to determine method accuracy and precision spiking blank matrix at 1 MRL level which was determined as Limit of Quantification (LOQ) of the method. A $100 \mu$ l of mixture of pesticides: Acephate, Aldrin, Amitraz, Azinphos-ethyl, Azinphos-methyl, BHC-alpha, BHC-beta, BHC-delta, BHCgamma, Carbaryl, Carbofuran, Chlorfenvinphos, Chlorpyrifos, Chlorpyrifos-methyl, Cyfluthrin I, Cyfluthrin II, Cyfluthrin III, Cyfluthrin IV, Cyhalothrin (lambda), Cypermethrin I (Zeta), Cypermethrin II, Cypermethrin IV, DDD-o, p', DDD-p, p', DDE-o,p', DDE-p,p', DDT-o,p', DDTp,p', Deltamethrin, Diazinon, Dichlorvos, Dieldrin, Dimethoate, Disulfoton, DMF, Endosulfan alpha, Endosulfan beta, Endosulfan sulfate, Endrin, Ethion, Fenitrothion, Fenpropathrin, Fenvalerate I, Fenvalerate II, Flumetralin, Heptachlor, Heptachlor epoxido, Hexachlorobenzene, Methidathion, Methoxychlor, p,p'-, Mevinphos, Mirex, PCB \#101, PCB \#138, PCB \#153, PCB \#180, PCB \#28, PCB \#52, Pirimiphos-methyl, Propoxur, ranged from $5 \mathrm{ng} / \mu \mathrm{l}$ to $10 \mathrm{ng} / \mu \mathrm{l}$ were used.
Calibration curves were prepared at six levels in concentrations ranging from 0.004 to 0.1 according to MRL and the substance. The results from the spiked samples were used to calculate the CC alpha and CC beta which ranged from 0.0002 to 0.003 for CC alpha and 0.0043 to 0.055 for CC beta.

The GC/MS/MS triple quadrupole system was configured according to the Agilent Pesticide Analyzer 412 configuration, featuring a 2 units of $15 \mathrm{~m}$ analytical column with midcolumn backflush.

\section{Conditions, GC}

Two methods were used during the analysis, a screening method with around 260 active substances with 40 minutes run time and quantification method.

Quantification, calibration curve and CC alpha/CC beta parameters were obtained by a total of $20.75 \mathrm{~min}$ run time and retention time locking to chlorpyrifos-methyl at 9.143. The method characteristics are: Agilent GC 7890A with column: Agilent J\&W HP-5msUI, $15 \mathrm{~m} \times 0.25 \mathrm{~mm}$, $0.25 \mu \mathrm{m}$ (2 units); Inlet: Split/splitless; Inlet liner: Splitless, single taper, Ultra Inert liner with glass wool; Carrier: Helium, Inlet flow (column 1): $1 \mathrm{~mL} / \mathrm{min}$ (constant flow mode) during run, 2 psi during backflush, PUU flow (column 2): column 1 flow $+0.2 \mathrm{~mL} / \mathrm{min}$; Inlet temp: $280^{\circ} \mathrm{C}$; Inj. Vol.: $1 \mu \mathrm{L}$; Purge flow to split vent: 30 $\mathrm{mL} / \mathrm{min}$ at $0.75 \mathrm{~min}$; Gas saver: On $(20 \mathrm{~mL} / \mathrm{min}$ at 2.0 min); Oven temp: $60^{\circ} \mathrm{C}(1 \mathrm{~min}), 40^{\circ} \mathrm{C} / \mathrm{min}$ to $170^{\circ} \mathrm{C}$ $(0 \mathrm{~min}), 10^{\circ} \mathrm{C} / \mathrm{min}$ to $310^{\circ} \mathrm{C}(0 \mathrm{~min}), 16^{\circ} \mathrm{C} / \mathrm{min}$ to $280^{\circ} \mathrm{C}(3$ $\min )$.

The screening method also locked for chlorpyrifosmethyl at $18.811 \mathrm{~min}$. and a total run of $40.5 \mathrm{~min}$. The same equipment with change at Oven temp: $60^{\circ} \mathrm{C}(1 \mathrm{~min})$, $40^{\circ} \mathrm{C} / \mathrm{min}$ to $120^{\circ} \mathrm{C}(0 \mathrm{~min}), 40^{\circ} \mathrm{C} / \mathrm{min}$ to $310^{\circ} \mathrm{C}(0 \mathrm{~min})$, $5^{\circ} \mathrm{C} / \mathrm{min}$.

\section{Conditions, MS}

Spectrometer: Agilent 7000B Triple Quadrupole GC/MS System; Electron Impact; transfer line temp: $280^{\circ} \mathrm{C}$; solvent delay: $2.3 \mathrm{~min}$; source temp: $300^{\circ} \mathrm{C}$ and Quadrupole temp: $\mathrm{Q} 1$ and $\mathrm{Q} 2=180^{\circ} \mathrm{C}$.

\section{Results and Discussion}

The UHT and pasteurized bovine milk were purchased at local groceries. Fourteen brands were selected and purchased twice; half in the middle of the year and the rest in the end of the year. These separate purchases were intended to have two sets of samples to check if the 
application of parasite control drug on the animals will differ by season.

The blank samples were spiked with concentrations of $1 \mathrm{MRL}$, most of the compounds listed before had recovery in the range of 60 to $120 \%$ and RSD below 20\%, frequently used for routine analysis using multi-residues methods [13]. Spiked samples presented some interesting results: the acaricide amitraz, frequently used for tick control was decomposed to DMF (N-(2, 4dimethylphenyl) formamide) metabolite and DMA (low level). The $\mathrm{pH}$ of the extract probably interfered the stability of this compound, which was observed the same by Hornish, et al., Korta, et al Marutoiu, et al. [14-17] Another metabolite, the DMA $(2,4$ dimethyl formanilidine), was used to calculate the concentration of amitraz. The organophosphorus insecticide trichlorfon also was metabolized to dichlorvos. For this reason, the concentration of dichlorvos was out of the recovery range not making possible to determine the exact value for this compound. The decomposition of trichlorfon to dichlorvos happens due to the high temperature of GC inlet [18].

Total of 28 samples were analyzed and the results using the CC alpha/CC beta, LOD/LOQ parameters were: positive to chlorpyrifos: 19 samples; one sample positive to cyproconazole+chlorpyrifos; 15 samples positive for cypermethrin+chlorpyrifos; one sample positive for prometrin+chlorpyrifos+cypermethrin; one sample positive for fluquinconazole and one sample positive for tebuconazole+chlorpyrifos.

\begin{tabular}{|c|c|c|c|}
\hline Pesticide & \multicolumn{3}{|c|}{ Pesticides found in the samples } \\
\hline & $>$ Ccalpha/CCbeta & >LOD & >LOQ \\
\hline Chlorpyrifos & 19 & 4 & \\
\hline Cyproconazole & 1 & & \\
\hline Cypermethrin & 15 & & 1 \\
\hline Fluquinconazole & 1 & & \\
\hline Prometrin & 1 & & \\
\hline Tebuconazole & 1 & & \\
\hline
\end{tabular}

Table 1: Positive samples according to $\mathrm{CC}$ alpha/CC beta, above LOD and LOQ parameters.

The screening method were created to identify more compounds and quantitation method from spiked samples made possible to quantify the pesticides chlorpyrifos in four samples and cypermethrin in one sample, all below LOQ but above LOD. Table 1 shows the recoveries of pesticides in the quantification method. Samples detected with chlorpyrifos, had its concentrations of $0.0022,0.003,0.0033$ and 0.0026 $\mathrm{mg} / \mathrm{kg}$. The LOD ranged from 0.0005 to 0.03 , chlorpyrifos is $0.002 \mathrm{mg} / \mathrm{kg}$ and LOQ ranged from 0.004 to 0.1 , chlorpyrifos was $0.01 \mathrm{mg} / \mathrm{kg}$. For cypermethrin the LOQ is 0.1 and LOD is $0.0290 \mathrm{mg} / \mathrm{kg}$ and concentration detected in the sample was $0.0370 \mathrm{mg} / \mathrm{kg}$.

\begin{tabular}{|c|c|c|c|c|c|c|c|c|c|c|}
\hline & Analyte & Brazil & Codex & Matrix & LOD & LOQ & Rec \% & RSD \% & $\begin{array}{c}\text { Measurement } \\
\text { uncertainty - } \\
\text { Codex b }\end{array}$ & Accreditate \\
\hline & & IN 13 & $\mathbf{2 0 1 5}$ & & & & & $\mathbf{n = 6}$ & Horwitz & yes/no \\
\hline 1 & Acephate & 0.02 & 0.02 & cow milk & 0.0041 & 0.02 & 94 & 7.3 & 0.0115 & yes \\
\hline 2 & Aldrin & 0.004 & 0.006 & cow milk & 0.0009 & 0.004 & 106 & 7.5 & 0.0029 & yes \\
\hline 3 & Amitraz & & 0.01 & cow milk & 0.0045 & 0.01 & 125 & 11.7 & 0.0064 & yes \\
\hline 4 & Azinphos-ethyl & 0.05 & & cow milk & 0.0101 & 0.05 & 105 & 6.4 & 0.0251 & yes \\
\hline 5 & Azinphos-methyl & 0.05 & & cow milk & 0.0101 & 0.05 & 104 & 6.5 & 0.0251 & yes \\
\hline 6 & BHC-alpha & 0.008 & & cow milk & 0.0015 & 0.008 & 107 & 5.9 & 0.0053 & yes \\
\hline 7 & BHC-beta & 0.008 & & cow milk & 0.0017 & 0.008 & 108 & 6.5 & 0.0053 & yes \\
\hline 8 & BHC-delta & 0.008 & & cow milk & 0.0019 & 0.008 & 105 & 7.5 & 0.0053 & yes \\
\hline 9 & BHC-gamma & 0.004 & & cow milk & 0.0009 & 0.008 & 107 & 7.3 & 0.0029 & yes \\
\hline 10 & Carbaryl & 0.02 & 0.05 & cow milk & 0.0104 & 0.05 & 109 & 15.9 & 0.0115 & yes \\
\hline 11 & Carbofuran & 0.1 & 0.05 & cow milk & 0.0369 & 0.1 & 106 & 11.6 & 0.0453 & yes \\
\hline 12 & Chlorfenvinphos & 0.01 & 0.01 & cow milk & 0.0022 & 0.01 & 116 & 6.5 & 0.0064 & yes \\
\hline 13 & Chlorpyrifos & 0.01 & 0.02 & cow milk & 0.0022 & 0.01 & 111 & 6.7 & 0.0064 & yes \\
\hline 14 & Chlorpyrifos-methyl & & & cow milk & 0.0024 & 0.01 & 109 & 7.3 & 0.0064 & yes \\
\hline 15 & Cyfluthrin I & 0.04 & 0.01 & cow milk & 0.0102 & 0.04 & 112 & 7.7 & 0.0208 & yes \\
\hline 16 & Cyfluthrin II & & & cow milk & 0.0117 & 0.04 & 105 & 9.2 & 0.0208 & yes \\
\hline 17 & Cyfluthrin III & & & cow milk & 0.0178 & 0.04 & 93 & 15 & 0.0208 & yes \\
\hline
\end{tabular}




\section{Advances in Clinical Toxicology}

\begin{tabular}{|c|c|c|c|c|c|c|c|c|c|c|}
\hline 18 & Cyfluthrin IV & & & cow milk & 0.0126 & 0.04 & 111 & 9 & 0.0208 & yes \\
\hline 19 & Cyhalothrin (lambda) & 0.025 & 0.2 & cow milk & 0.0072 & 0.2 & 97 & 9.8 & 0.0815 & yes \\
\hline 20 & Cypermethrin I (Zeta) & 0.1 & 0.05 & cow milk & 0.029 & 0.1 & 108 & 8.9 & 0.0453 & yes \\
\hline 21 & Cypermethrin II & & & cow milk & 0.0328 & 0.1 & 103 & 10.7 & 0.0453 & yes \\
\hline 22 & Cypermethrin IV & & & cow milk & 0.0234 & 0.1 & 107 & 7.2 & 0.0453 & yes \\
\hline 23 & DDD-o,p' & 0.01 & & cow milk & 0.0017 & 0.01 & 106 & 5.3 & 0.0064 & yes \\
\hline 24 & DDD-p,p' & 0.01 & & cow milk & 0.0023 & 0.01 & 111 & 6.8 & 0.0064 & yes \\
\hline 25 & DDE-o,p' & 0.01 & & cow milk & 0.0018 & 0.01 & 120 & 5 & 0.0064 & yes \\
\hline 26 & DDE-p,p' & 0.01 & & cow milk & 0.002 & 0.01 & 104 & 6.3 & 0.0064 & yes \\
\hline 27 & DDT-o,p' & 0.01 & 0.02 & cow milk & 0.0016 & 0.01 & 108 & 5 & 0.0064 & yes \\
\hline 28 & DDT-p,p' & 0.01 & 0.02 & cow milk & 0.0017 & 0.01 & 100 & 5.7 & 0.0064 & yes \\
\hline 29 & Deltamethrin & 0.03 & 0.05 & cow milk & 0.0158 & 0.03 & 103 & 17.1 & 0.0163 & yes \\
\hline 30 & Diazinon & 0.01 & 0.02 & cow milk & 0.0021 & 0.01 & 113 & 6 & 0.0064 & yes \\
\hline 31 & Dichlorvos & & 0.01 & cow milk & 0.0056 & 0.01 & 137 & 13.7 & 0.0064 & yes \\
\hline 32 & Dieldrin & 0.004 & 0.006 & cow milk & 0.0005 & 0.004 & 113 & 3.7 & 0.0029 & yes \\
\hline 33 & Dimethoate & & 0.05 & cow milk & 0.0019 & 0.01 & 108 & 5.8 & 0.0064 & yes \\
\hline 34 & Disulfoton & & 0.01 & cow milk & 0.0021 & 0.01 & 108 & 6.4 & 0.0064 & yes \\
\hline 35 & DMF & & & cow milk & 0.0015 & 0.01 & 107 & 4.7 & 0.0064 & yes \\
\hline 36 & Endosulfan alpha & & 0.01 & cow milk & 0.0028 & 0.01 & 105 & 9 & 0.0064 & yes \\
\hline 37 & Endosulfan beta & & 0.01 & cow milk & 0.0023 & 0.01 & 115 & 6.5 & 0.0064 & yes \\
\hline 38 & Endosulfan sulfate & & 0.01 & cow milk & 0.0021 & 0.01 & 110 & 6.4 & 0.0064 & yes \\
\hline 39 & Endrin & 0.004 & 0.006 & cow milk & 0.0011 & 0.004 & 119 & 7.7 & 0.0029 & yes \\
\hline 40 & Ethion & & & cow milk & 0.0024 & 0.01 & 113 & 7.1 & 0.0064 & yes \\
\hline 41 & Fenitrothion & & 0.01 & cow milk & 0.0024 & 0.01 & 115 & 7 & 0.0064 & yes \\
\hline 42 & Fenpropathrin & & 0.1 & cow milk & 0.0186 & 0.1 & 107 & 5.8 & 0.0453 & yes \\
\hline 43 & Fenvalerate I & 0.04 & 0.1 & cow milk & 0.0136 & 0.04 & 101 & 11.2 & 0.0208 & yes \\
\hline 44 & Fenvalerate II & & & cow milk & 0.0075 & 0.04 & 104 & 6 & 0.0208 & yes \\
\hline 45 & Flumetralin & & & cow milk & 0.0025 & 0.01 & 112 & 7.5 & 0.0064 & yes \\
\hline 46 & Heptachlor & 0.004 & 0.006 & cow milk & 0.0007 & 0.004 & 109 & 5 & 0.0029 & yes \\
\hline 47 & Heptachlor epoxido & 0.004 & & cow milk & 0.0014 & 0.004 & 111 & 10.4 & 0.0029 & yes \\
\hline 48 & Hexachlorobenzene & 0.008 & & cow milk & 0.0014 & 0.008 & 101 & 5.8 & 0.0053 & yes \\
\hline 49 & Methidathion & 0.02 & 0.001 & cow milk & 0.0046 & 0.02 & 114 & 6.8 & 0.0115 & yes \\
\hline 50 & Methoxychlor, p,p'- & 0.004 & & cow milk & 0.001 & 0.004 & 115 & 6.9 & 0.0029 & yes \\
\hline 51 & Mevinphos & 0.05 & & cow milk & 0.0082 & 0.05 & 110 & 5 & 0.0251 & yes \\
\hline 52 & Mirex & 0.004 & & cow milk & 0.0006 & 0.004 & 95 & 5.6 & 0.0029 & yes \\
\hline 53 & PCB \#101 & 0.008 & & cow milk & 0.0015 & 0.01 & 110 & 4.6 & 0.0064 & yes \\
\hline 54 & PCB \#138 & 0.008 & & cow milk & 0.0018 & 0.01 & 102 & 5.7 & 0.0064 & yes \\
\hline 55 & PCB \#153 & 0.008 & & cow milk & 0.0019 & 0.01 & 102 & 6.3 & 0.0064 & yes \\
\hline 56 & PCB \#180 & 0.008 & & cow milk & 0.0015 & 0.01 & 98 & 5.3 & 0.0064 & yes \\
\hline 57 & PCB \#28 & 0.008 & & cow milk & 0.0017 & 0.01 & 115 & 4.8 & 0.0064 & yes \\
\hline 58 & PCB \#52 & 0.008 & & cow milk & 0.0018 & 0.01 & 113 & 5.4 & 0.0064 & yes \\
\hline 59 & Pirimiphos-methyl & 0.05 & 0.01 & cow milk & 0.0089 & 0.05 & 116 & 5.1 & 0.0251 & yes \\
\hline 60 & Propoxur & 0.05 & & cow milk & 0.0133 & 0.05 & 107 & 8.2 & 0.0251 & yes \\
\hline
\end{tabular}

Table 2: Maximum residues levels from Brazil (b, 2015), Codex alimentarius and recovery results [19].

None of these substances detected hasMRL established by the government for milk samples. Fluquinconazole has a MRL for soybean; prometrin has MRL for cotton crop and tebuconazole can be employed in corn production and also as preservative for wood used to build the fences. The substances chlorpyrifos, cyproconazole and cypermethrin have a MRL established for corn and also as a preservative for wood fences. Chlorpyrifos and cypermethrin can be found in veterinary formulas to control ticks in cattle, and the milk cannot be consumedbefore 3 days after application. Their presence in the samples therefore, could be associated to intensive 
use of anti-parasite control (ticks), feed and environment exposure. The acute dietary ingestion (ADI) of such compounds are between $0.01 \mathrm{mg} / \mathrm{kg}$ to $0.05 \mathrm{mg} / \mathrm{kg}$. Since the values were below the LOQ the \% of ADI were not extrapolated.

Although milk and milk products participate as one of the most important food item in children, adult and elderly diet, in Brazil, most of the analysis is to control microbiological diseases, so anti-microbiological substances are frequently investigated. Some authors analyzed milk samples, Ciscato, et al. Heck, et al. Asmus, et al. Freguglia, et al., Pagnani, et al. $[20,5,21,22,6,7]$ in Brazil and they observed that organochlorine pesticides were the most important group evaluated. Another observation is that the major part of the contamination in milk is through feed. Heck, et al. [22] have evaluated the Northeast area of Brazil and related that feed contributed to pesticides residues in milk, especially organophosphorus, carbamates and pyrethroids, as presented in the present work.

Despite of organochlorine characteristics, such as environmental contaminant and accumulation in the fat tissues, it was used until 80's in Brazil. However, no residues of such compounds, even PCBs were found in the samples evaluated in this study, probably the high temperature and the removal of extra \% of fat (Brazilian milk has $3 \%$ of fat) contributed to decrease or to eliminate these substances.

Multiple residues were also observed in $80 \%$ of the positive samples, chlorpyrifos and cypermethrin were the main combination. Multiple findings could be a risk to human health and if the compounds share the same mode of action it could be a serious problem Boobis, et al. [23].

Individual compounds that are present at low levelswith no effects could result in a measurable effect when combined with compounds in same levels. All the substances found in this work have the ADI parameter between $0.01 \mathrm{mg} / \mathrm{kg}$ bw to $0.05 \mathrm{mg} / \mathrm{kg}$ bw. The acute reference dose (ARfD) does not exist for these substances, according to Jardim \& Caldas, 2009 only substances with potential carcinogenic or genotoxic have this parameter established [24-26].

\section{Conclusions}

The samples analyzed contained 3\% of fat and the presence of such substance did not interfere in the cleanup step. Therefor the QuEChERS method with C18 was enough and no further cleanup was necessary.
The compounds amitraz and trichlorfon, used as mite control in the cattle could be metabolized during the extraction or chromatographic analysis, probably because of the $\mathrm{pH}$ below 5.5 during extraction and by the injector's temperature. Dairy products with acid $\mathrm{pH}$ and the presence of some microorganisms can affect the analysis too.

The removal of extra fat content of the milk probably could interfere in the reduction of organochlorine pesticides in milk samples. Industrial treatments as pasteurization and ultra-high temperature could also reduce the presence of some pesticides. Therefore, although detecting residues of organophosphate pesticides in some samples, its concentrations did not represent a health concern.

Monitoring studies and methods which demands a short time of analysis are important to evaluate the food quality, especially for those like milk due to the large consumption of this product mainly by the infants, that compared to adults, toxicity level is more significant by their low mass weight.

\section{Acknowledgements}

The authors would like to thank Agilent Technologies for providing QuEChERS consumable and technical support.

\section{References}

1. MAPA (2015) Ministério da Agricultura, Pecuária e Abastecimento [internet]c. Manual de Garantia da Qualidade Analítica.

2. Li Z (2018) Health risk characterization of maximum legal exposures for persistent organic pollutant (POP) pesticides in residential soil: An analysis. J Environ Manage 205: 163-173.

3. Li Z and Jennings A (2018) Global variations in pesticide regulation and health risk assessment of maximum concentration levels in drinking water. J Environ Manage 212: 384-394.

4. Ministério da Agricultura, Pecuária e Abastecimento [internet]b. Instrução Normativa no 13 de 15 de julho de 2015.

5. Ciscato CHP, Gebara AB, Spinosa H (2004) Resíduo de Pesticidas em Leites Bovino e Humano. R Ecotoxicol e Meio Ambiente Curitiba 14: 25-38. 


\section{Advances in Clinical Toxicology}

6. Freguglia RMO, Moura-Andrade GCR, Tornisielo VL (2010) Determinação de resíduos de organoclorados no leite em pó distribuído em Piracicaba (SP). Revista de Ecotoxicologia e meio Ambiente 20: 35-42.

7. Pagnani R, Beloti V, Battaglini AP, Dunga KS, Tamanini R (2011) Organophosphorus and carbamates residues in milk and feedstuff supplied to dairy cattle. Pesq Vet Bras 31(7): 598-602.

8. Codex Alimentarius [internet]. International Food Standard.

9. SEBRAE (2014) Agrotóxicos no Leite: Como evitar esses resíduos e conquistar o mercado [internet]. Santa Catarina, Brasil. Leite Relatório de Inteligência.

10. Ministério do Planejamento e Gestão-IBGE (Instituto Brasileiro de Geografia e Estatística) [internet]. Análise do Consumo Alimentar Pessoal no Brasil.

11. Jardim ANO, Caldas ED (2009) Exposicao humana a substâncias potencialmente toxicas na dieta e os riscos para saude. Quimica Nova 32(7): 1898-1909.

12. Thompson M, Ellison SLR, Woos R (2002) Harmonized guidelines for single-laboratory validation of methods of analysis (IUPAC Technical Report, 1999). Pure Appl Chem 74(5): 835-855.

13. SANTE 12571/2015 - Guidance document on analytical quality control and method validation procedures for pesticides residues analysis in food and feed.

14. Hornish RE, Clasby MA, Nappier JL, Nappier JM, Hoffman GA (1984) Total residue analysis of amitraz [1, 5 Bis (2,4-dimethylphenyl)-3-methyl-1, 3, 5_triazapenta-1, 4-diene] residues in fruit and soil samples by electron capture gas chromatography. J Agric Food Chem 32(6): 1219-1223.

15. Korta E, Bakkali A, Berrueta LA, Gallo B, Vicente F (1999) Kinetics and mechanism of amitraz hydrolysis in aqueous media by HPLC and GCMS. Talanta 48(1): 189-199.

16. Korta E, Bakkali A, Berrueta LA, Gallo B, Vicente F, et al. (2003) Determination of amitraz and other acaricide residues in beeswax. Analytica Chimica Acta 475(1-2): 97-103.
17. Marutoiu OF, Gogoasa I, Tofana M, Marutoiv C, Baghera N, et al. (2011) Separating and identifying pesticides in milk through thin layer chromatography and mass spectrometry. Journal of. Agroalimentary Processes and Technologies 17(3): 252-260.

18. Nogh M, Cullison R (1996) Determination of trichlorfon and dichlorvos residues in shrimp using gas chromatography with Nitrogen-Phosphorus detection. J Agric Food Chem 44(9): 2686-2689.

19. Codex Alimentarius [internet]b Guidelines on estimation of uncertainty of results (CAC/GL 592006).

20. Ciscato CHP, Gebara AB, Spinosa Hde S (2002) Pesticideresidues in cowmilkconsumed in Sao Paulo City (brazil). J Environ Sci Health B 37(4): 323-330.

21. Heck MC, Sandos JS, Bogusz Junior S, Costabeber I, Emanuele T (2007) Estimation of children exposure to organochlorine compounds through milk in Rio Grande do Sul, Brazil. Food Chemistry 102(1): 288294.

22. Asmus CIRF, Alonzo HGA, Palacios M, Silva AP, Filhote MIF, et al. (2008) Assessment of human health risk from organochlorine pesticide residues in Cidade dos Meninos, Duque de Caxias, Rio de Janeiro, Brazil. Cad Saude Publica 24(4): 755-766.

23. Boobis AR, Ossendorp BC, Banansiak U, Hamey PY, Sebestyen I, et al. (2008) Cumulative risk assessment of pesticide residues in food. Toxicol Lett 180(2): 137-150.

24. Ministério da Agricultura, Pecuária e Abastecimento [internet]a. Portal Brasil - Ministério da Agricultura quer fomentar o consumo de leite.

25. Cunha SC, Lehotay SJ, Mastovska K, Fernandes JO, Oliveira PP, et al. (2007) Evaluation of the QuEChERS sample preparation approach for the analysis of pesticide residues in olives. J Sep Sci 30(4): 620-632.

26. Lehotay SJ, Mastovska K, Yun SJ (2005) Evaluation of two fast and easy methods for pesticide residue analysis in fatty food matrixes. J AOAC Int 88(2): 630638. 